\title{
INDUSTRY CONCENTRATION AND GROWTH IN PHILIPPINE AGRICULTURE
}

\author{
Karen Debbie J. Cosrojas ${ }^{1 *}$, Rec E. Eguia ${ }^{2}$ \\ ${ }^{1}$ Department of Agricultural Economics, College of Agriculture / Central Mindanao University, Philippines \\ ${ }^{2}$ College of Development Management, University of Southeastern Philippines, Philippines \\ *corresponding author: debbiecosrojas@gmail.com
}

\begin{abstract}
The study investigated the extent of relationship of the agriculture industry concentration and growth of Philippine agriculture. Specifically, it determined the key agriculture sub-sectors in each region in the Philippines and investigated the regional industry concentration and economic performance nexus. The objectives were achieved using secondary data for the 16 regions in the Philippines. Location Quotient (LQ) and correlation analysis were used as tools to make sense of the data. Results show a number of key industries in each region which from the assumptions of the LQ formed the economic base of the region. The findings show non-significant correlation between regional industry concentration and the GVA for agriculture. This suggested for further investigation of the concentration or diversity relationship to economic performance.
\end{abstract}

Keywords: economic base, industry concentration, location quotient, Philippine agriculture

\section{INTRODUCTION}

The development in the agriculture sector is considered as one of the most powerful tools to alleviate extreme poverty, boost shared prosperity and feed a projected 9.7 billion people by 2050 (World Bank, 2017). The World Bank further discussed that the growth in the agriculture sector is two to four times more effective in raising incomes among the poorest compared to other sectors. According to the 2016 analysis, there are $65 \%$ of poor working adults made a living out of agriculture. In the Philippines, the Agriculture, Fisheries, and Forestry (AFF) sector is fundamental in generating employment for about a third of the country's labor force (PDP, 2017). This results to reducing poverty and inequality for the three-fourths of the poor who are in the rural areas.

However, the agriculture sector's development indicators have been declining over time. At the worldwide scale, the World Bank data shows a declining percent share of the AFF sectors to Gross Domestic Product (GDP), from the $4.96 \%$ in 2000 to
$3.54 \%$ in 2016. In the Philippines, the contribution of agriculture sector to the country's GDP recorded an annual average GDP share of 10\% from 2013 to 2015 (PSA,2015).

The declining trend in the agriculture sector is beset with a number of constraints. Investment is one of the limiting factors to agricultural production capacity which also shows a declining trend both in the public and private investments (Zepeda, No Date). Countries especially the developing ones are faced with budget constraints to finance investments. In the Philippines, Aquino et.al (2013) cited that public expenditure in agriculture was fairly low relative to the size of total government spending.

Concentration and specialization of the industry is another option for the mentioned dilemma. Geographic concentration of a specific industry reflects the distribution of its regional shares. A highly concentrated industry will have a very large part located in a small number of regions (Goschin et. al, No Date). 
Concentrations are gaining recognition in the spatial distribution of economic activity in economies worldwide. Sheppard and Zhao (2016) notes that clusters play significant roles in influencing the range of economic activities available, input productivity, and even international trade flows. Concentration analysis is important in understanding what makes a region's economy unique.

Morgan (2004), Pontus and Borgman (2004), Hollis (2003) and Boason (2002) were among the studies that found a positive relationship between regional industrial concentration and economic performance. Most of these studies focused on the manufacturing industries (Morgan, 2004 and Hollis, 2003) in the United States (Pontus and Borgman, 2004 and Boason, 2002) and one in Turkey (Morgan, 2004). The literature review shows that there are no studies and empirical findings on the agriculture industry concentration in the Philippines, thus, this study.

The main purpose of the study was to investigate the extent of relationship of industry concentration and agriculture growth in the Philippine agriculture.

It identified the key agriculture sub-sectors in each region in the Philippines and determine the extent of relationship between industry concentration and agriculture growth.

Specialization and concentration are of particular interest given the empirical support on its positive effects to economic performance indicator. Identification of key agriculture industry in each region is found important because leading industries play a critical role for structural changes and export performance of the countries (Imbs et. al, 2012). Hence, this established the ground of conducting the study that focused on the Philippine agriculture sector.

\section{RESEARCH METHODS}

The study covered the 16 administrative regions in the Philippines. The country has a total land area of $300,000 \mathrm{~km}^{2}$. Area devoted to agriculture is posted at 9.67 million hectares in 2002 .

Basically, the number of employments in the agriculture sub-sector is the major data obtained from the Census of Philippine Business and Industry (CPBI). Another secondary data utilized was the GVA in agriculture in each region which was sourced from the Regional Accounts of the Philippines from the Philippine Statistics Authority (PSA).

The identification of key industries in each region in the Philippines was determined using location quotient (LQ) and the extent of relationship between industry concentration and agriculture growth was determined using correlation.

LQ is one of the oldest and still widely used analytical tools used by regional economists (Miller et al. 1991). It represents a good starting point for understanding the regional economy and providing information to support regional planning efforts.

The following is the basic formula for calculating location quotients based on the Minimum Requirements approach:

\section{Total Employment in the Agri-sub-sector in the Region Total Employment in Agri sector the Region \\ $\mathrm{LQ}=$ \\ Total Employment in the Agri-subsector in the Philippines \\ Total Employment in the Agri-sector in the Philippines}

The Minimum Requirement technique is one of the three approaches in the calculation of LQ based on the assumptions. This approach assumes that any industry can be either export or serviceoriented depending on its relative concentration in a region.

$\mathrm{LQ}=1.0$ means that the location/region has the same percentage of employment in a particular industry as found nationally and as such, all employment is non-basic.

LQ $<1.0$ implies that local employment in a particular industry is less than expected and not even meeting local demand for a given good or service.

The term LQ > 1.0 implies that local employment is greater than expected and therefore assumes basic industries within the local economy.

Correlation is primarily concerned with finding out whether a relationship exists and with determining its magnitude and direction (Ho, 2006). Specifically, the study used the Pearson Product Moment of Correlation coefficient considering the level of measurement for the variables which are interval or ratio. The data were standardized using $\mathrm{Z}$ scores because the data have different scales and means. The correlation analysis was run using SPSS.

The values of the correlation coefficients vary between +1.00 and -1.00 . Both of these extremes represent perfect relationships between the variables, and 0.00 represents the absence of a relationship. The relationship could be a positive (positive coefficient) or negative relationship (negative coefficient). The strength of the relationship between the variables can be explained by its coefficient value. Coefficient value of \pm 0.0 to \pm 0.20 is very low; \pm 0.21 to \pm 0.40 is low; \pm 0.41 to \pm 0.60 is moderate; \pm 0.61 to \pm 0.80 is high; and \pm 0.81 to \pm 1.0 is Very High. 


\section{RESULTS AND DISCUSSION}

\section{Key Agriculture Sub-sector in Regions in the Philippines}

LQ coefficient are presented in bar graphs and bubble graphs. Bar graphs were used for regions where the available data is only for a year commonly in 2012 only. Meanwhile, for regions with series of data from 2009 to 2012, LQ were presented in bubble graphs.

In the bubble graph, the vertical axis has the basic LQ measurement, while the horizontal axis shows the average percent change in LQ over time. Agriculture industry entities are plotted as circles (or "bubbles"), with the circle size corresponding to their LQ value.

An industry located in the upper right quadrant implies that the industry is more concentrated in the region than average and is becoming more concentrated over time indicated by the positive percent change. These industries are "standouts" that distinguish the regional economy and are doing so more every year. Further, large industries in this quadrant are both important and high performing, which means they will have increasing workforce demand. Small industries in this quadrant are emerging, high-potential regional export industries that should be developed further (EMSI, No Date).

The industry located in the left quadrant are more concentrated in the region than average, but whose concentration is declining. If a mid-size or large industry or cluster is in this quadrant, it is an important warning that the region is losing a major part of its export base and should form planning and investment priorities accordingly. If the region does not bolster these industries or replace them with other export industries, it will likely enter a general recession (EMSI, No Date).

\section{National Capital Region}

Figure 1 shows the National Capital Region's agriculture sub-sectors location quotients. There were three (3) identified agriculture industry which are concentrated in the region (LQ of more than 1). This result reveals the higher specialization of these industries in the region than in the national level in terms of employment.

Farm machineries rental is tagged with the highest LQ value with 10.41 which means that farm machineries is 10 times more concentrated in the region than average. This industry is only found in NCR that could be attributed to the availability of farm machineries in the region given its highly urbanized characteristic. However, the data obtained from this industry is only in 2012 thus, percent change over time is not computed and this only gave a snapshot of the industry.
Production or growing of horticultural specialties and nursery products are nearly 3 times more concentrated in NCR than average and with a positive average percent change over time. The positive percent change indicates that the industry is growing over time.

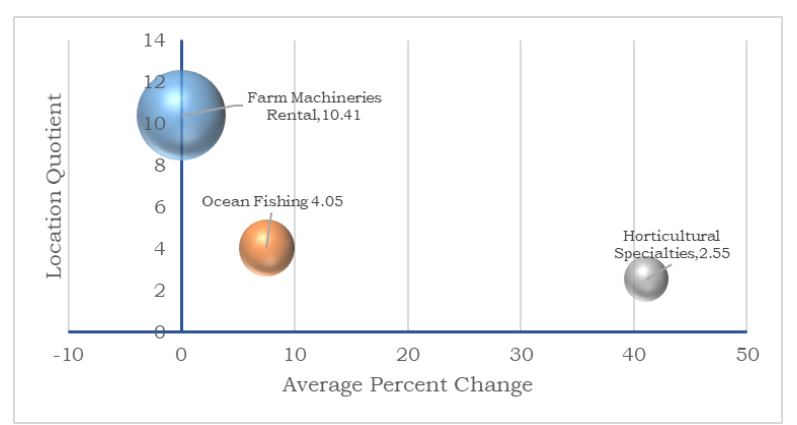

Figure 1. Agriculture sub-sector average location quotient, NCR, 2006-2012

Ocean fishing is another concentrated industry in NCR with LQ of 4 and the average percent change of $8 \%$. This industry could also be tagged as a banner industry in the region. In the 2015 Annual Survey of Philippine Business and Industry (ASPBI), ocean fishing ranked $4^{\text {th }}$ with the greatest number of workers. In terms of the volume of production, NCR accounts $2.89 \%$ to total volume of fisheries in 2016 (PSA, 2017).

\section{Ilocos Region}

In Ilocos Region, ten (10) agriculture industry sub-sectors are found to have more than 1 LQ coefficient as shown in Figure 2. Among the top industry sub-sectors in the region are operation of marine fish tanks, pens, cage except fish breeding farms and nurseries in sea water (77.52), growing of fruit bearing vegetables (57.03), and coastal fishing (21.92). In lesser LQ values are operation of freshwater fishpond and chicken broiler production.

The region recorded the highest LQ in the growing of fruit bearing vegetables such as tomato, eggplant, cucumber, ampalaya and others. Further, the region has the second highest LQ in coastal fishing next to Bicol Region. In the 2015 annual survey of Philippine Business and Industry Agriculture, Forestry and Fishing Establishments with total employment of 20 and over, fishing accounts $10.6 \%$ in terms of the number of establishments in the national scale. In terms of volume of production, among the provinces in Ilocos, Pangasinan accounts the highest volume which is $86 \%$ of the total volume in the region in 2016 (Fisheries Statistics, 2017). 


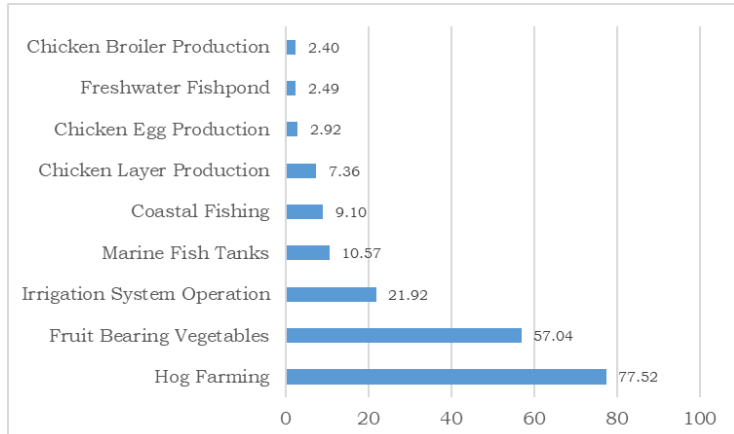

Figure 2. Agriculture sub-sector location quotient, Ilocos Region, 2012

\section{Cagayan Valley}

Irrigation system operation and chicken production are two of the industries with more than 1 LQ in Cagayan Valley as displayed in Figure 3. The irrigation system operation is 10 times more concentrated in the region than the average and this is also the highest concentration for the industry compared to other regions.

Chicken broiler production is nearly 9 times more concentrated in the region than average. In the 2015 ASPBI, animal production, to which chicken production is under, is the led sector in the Philippine agriculture with the highest number of establishments of $365(31.8 \%)$. The concentration of this industry through its LQ value is comparable to Central Luzon and CALABARZON.

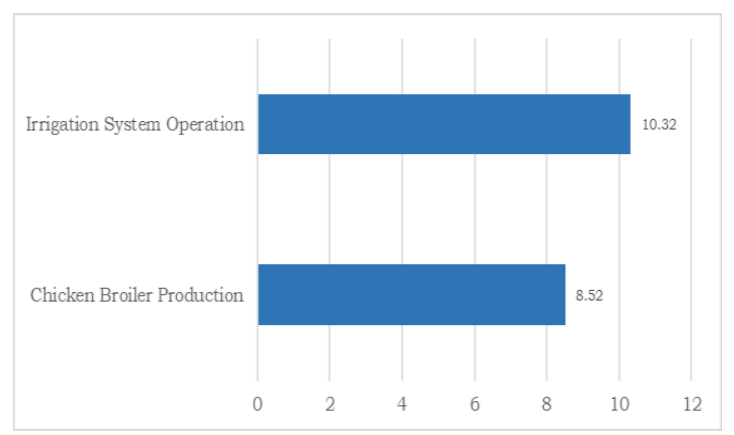

Figure 3. Agriculture's sub-sector Location

Quotient, Cagayan Valley, 2012.

\section{Central Luzon}

Figure 4 displays the agriculture sub-sectors in Central Luzon. As can be gleaned, these industries or sub-sectors are in the left part of the quadrant. These industries are concentrated in the region, however declining. Generally, this implies that the region is losing a major part of its export base for these industries.

Chic

ken broiler is tagged with the highest LQ value which is 10 times more concentrated in the region than the average, however, declining at an average of around 6\% from 2009 to 2012. Moreover, contract animal growing is 4 times more concentrated in the region than average although this posted the highest average decline in LQ of nearly $80 \%$. The same is true for the operation of freshwater fish pens and fish cage. Given the declining trend, planning and investment priorities in these industries should be considered.

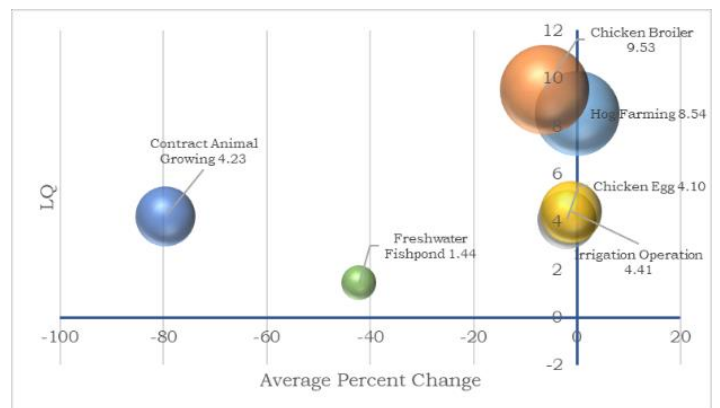

Figure 4. Agriculture Sub-sector Average Location Quotient, Central Luzon, 2006-2012

\section{Calabarzon}

CALA

BARZON is the region with the greatest number of sub-sectors with LQ of more than 1. Raising of game fowl tops on the list with nearly $35 \mathrm{LQ}$ value. However, the available data is only for 2012, thus, unable to compute for the percent change.

Displayed in Figure 5, the production of horticultural specialties and nursery products which is 12 times more concentrated in the region than the average. It is the only industry that posted positive percent change over time at an average of $5.4 \%$. Based on the assumption for LQ, this serves as an economic base of the region.

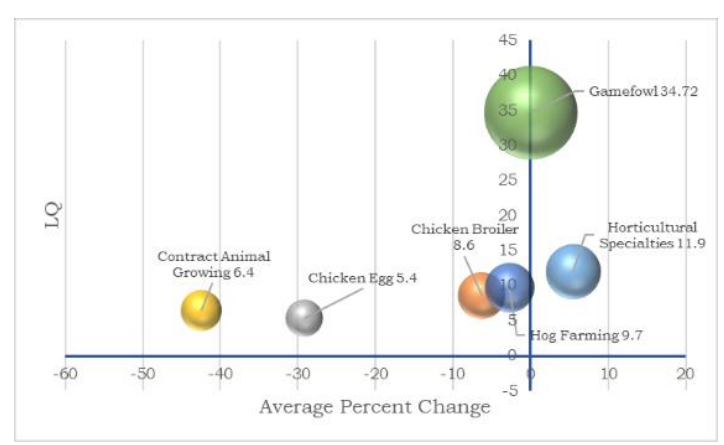

Figure 5. Agriculture sub-sector, average Location Quotient, CALABARZON, 2006-2012.

\section{Mimaropa}

In the bubble graph for the industries in MIMAROPA in Figure 6, almost all of the industries are aligned at the $\mathrm{Y}$-axis which means that the data 
available is only good for one year except for coastal fishing.

Coconut production is the leading industry in MIMAROPA in terms of its LQ of 33.01. The region is tagged with the highest LQ in growing coconut among the regions which is 33 times more concentrated than average. The coconut industry is the $2^{\text {nd }}$ highest number of employments in the region next to ocean fishing. Number of employments in the industry is $29 \%$ (791) to total employment of the agriculture sector in the region in 2012. This result could form an economic base of the region, more so, if the industry will have a positive increasing percent change (if only data are available for computation). The same goes true for the preparation of crops for primary markets.

Preparation of crops for primary markets has the second highest LQ value which is 20 times more concentrated than average. The region recorded the highest LQ value for this industry in the period under study. Although the industry only posted lesser number of employments in 2012.

Coastal fishing on the other hand is nearly 13 times more concentrated in the region than average. It is the industry with the highest number of employments in the agriculture sector in 2012 which accounts nearly $48 \%$ (1313) to the total number of employments. However, the industry shows a declining trend over time. Such that if there will be continuous decline of its LQ, it will have negative effects in the economy base on the assumptions of its LQ value.

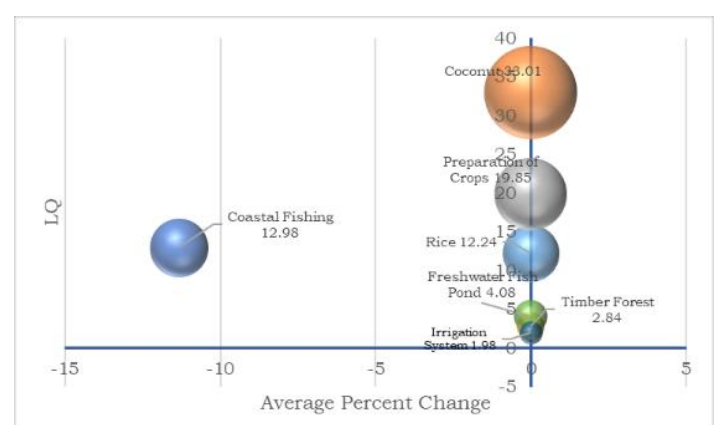

Figure 6. Agriculture sub-sector average Location Quotient, MIMAROPA, 2006-2012.

\section{Bicol Region}

Figure 7 shows Bicol Region's LQ for its different sub-sector where coastal fishing is found to be the highest. The region found to have the highest LQ in coastal fishing which is nearly 70 times more concentrated in the region than in the national. This sub-sector also posted the highest number of employments among the agriculture sub-sector in the region accounting to $36 \%$ in 2012 . Given these figures, the industry could form the region's economic base. The region's fisheries volume of production in the 2016 statistics is posted at 234, 396 metric tons which is $5.38 \%$ to the total Philippine volume of production.

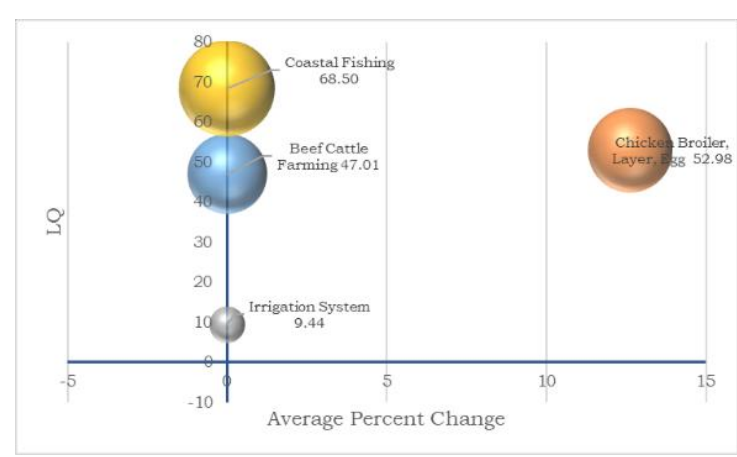

Figure 7. Agriculture sub-sector average Location Quotient, Bicol Region, 2006-2012

Other major industries of the region are on animal production such as chicken and beef cattle farming. In the 2015 Philippine annual survey in agriculture and fishery, animal production subsector ranks third with the greatest number of employments with 34,698 workers (23.9\%) (PSA, 2015). Across regions, Bicol noted to have the highest LQ for broiler and layer chicken production which is nearly 53 times more strenuous in the region than the national. The sub-sector is also observed to have a positive average percent change over time although the number of employments is only $3.61 \%$ to the total number of employments in the region in 2012. Having a high-LQ with a small number of jobs may be an export-oriented industry, but is not vital to the region's economy.

\section{Western Visayas}

Displayed in Figure 8 is the bubble graph showing Western Visayas five (5) agriculture subsectors with LQ of more than 1. Growing of fruit bearing vegetables like tomato, cucumber and its likes is the leading sub-sector with nearly 5 LQ followed by sugarcane and growing of tropical fruits. The first two sub-sectors with the highest LQ exhibit a positive percentage change in its LQ from 2016 to 2012.

Sugarcane production which is nearly 4 times more concentrated in the region than average forms the economic base among the agriculture subsector in the region as it accounts $84 \%(24,855)$ to the total employment in the agri-sector in the region in 2012. This is the highest number of employments among the regions in the Visayas which are into vast hectarage in sugarcane production. The region also tagged the highest LQ for this subsector.

Growing of fruit bearing vegetables is under the broad category of perennial crops which generated the highest employment in the national agriculture sector in the 2015 Annual Survey of Philippine Business and Industry Agriculture, Forestry and Fishing. 


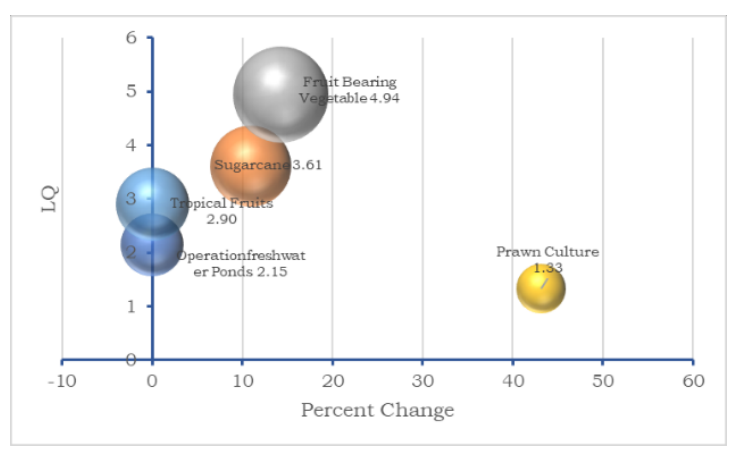

Figure 8. Agriculture sub-sector average Location Quotient, Western Visayas, 2006-2012.

On the other note, prawn culture sub-sector which displays the highest average percent change only accounts less than $1 \%$ to the total employment in the agriculture sector in the region in 2012. Again, a high-LQ industry with a small number of jobs may be an export-oriented industry but is not vital to the region's economy.

\section{Central Visayas}

Three of the agriculture sub-sectors in Central Visayas were having positive average percent change over time to include sugarcane production, hog farming and chicken egg production as exemplified in Figure 9. Sugarcane production forms the region's economic base as it accounts around $61 \%$ of the total number of employments in the agriculture sector in the region in 2012. In addition, this is considered as an export-oriented industry, which is important because they bring money into the region, rather than simply circulating money that is already in the region. Government and private support sector should consider developing the sector not only the jobs that they create but also its multiplier effect.

Moreover, coconut sub-sector which is 5 times more concentrated in the region than average has the highest LQ value. However, the number of employments is lower which is computed at $3.45 \%$ of the total employment in the region in 2012. This implies that the industry could be an export based but is not vital to the economy. Other potential industries having positive average LQ change are hog farming and chicken egg production.

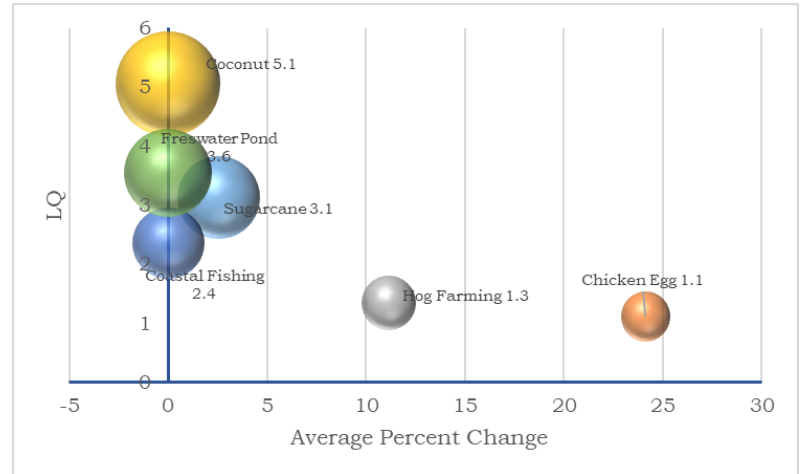

Figure 9. Agriculture sub-sector average Location Quotient, Central Visayas, 2006-2012

\section{Eastern Visayas}

The same with the previously mentioned regions in the Visayas, sugarcane production is also Eastern Visayas economic base as shown in Figure 10. Although it displays average negative percent in LQ through time, the industry has the highest number of employments contributing nearly $65 \%$ (2067) to the total number of employments in the region in 2012.

Meanwhile, preparation of crops for primary markets is with the highest LQ yet only contributes a lower number of employments posted at $1.16 \%$ to the total number of employments in the agriculture sector in the region in 2012. Pineapple growing can be considered as potential economic base in the region as it is 2 times more concentrated in the region than average and it accounts nearly $12 \%$ of the total number of employments in the agriculture sector in the region in 2012. This is the second highest employment generator next to sugarcane production. Contract animal growing also posts LQ greater than one and contributes nearly $5 \%$ to the total number of employments in the agriculture sector in the region in 2012.

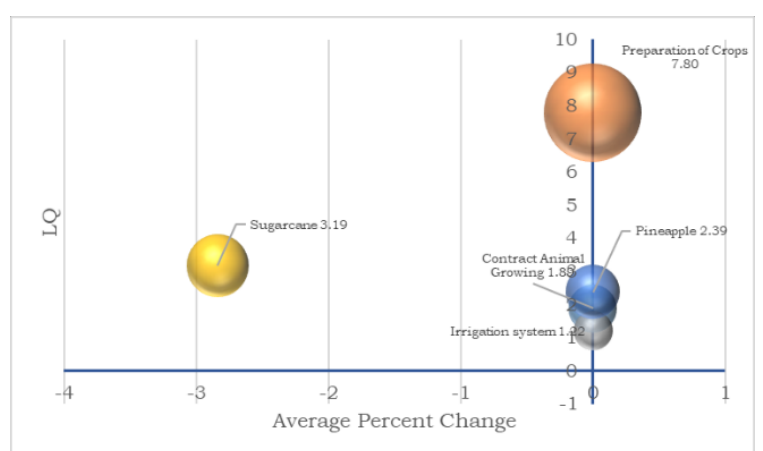

Figure 10. Agriculture sub-sector average Location Quotient, Eastern Visayas, 2006-2012.

\section{Zamboanga Peninsula}

Zamboanga Peninsula contributes around 3\% (5486) to the total number of employments in the agriculture sector in the Philippines in 2012. Figure 11 shows the industries that composed the said $3 \%$. 
Growing of rubber is 16 times more concentrated in the region than average. It is explicitly the only industry with a positive average percent change in its LQ coefficient. It accounts nearly $70 \%$ to the total number of employments in the agriculture sector in the region in 2012. Hence, this industry satisfies the criteria as an economic base of the region. Giving priority to this industry will have multiplier effect other than employment generation.

Meanwhile, operation of fish tanks is posted to have the highest LQ value which is nearly 20 times more concerted in the region than the average. In terms of its share to the total number of employments in the region in the period under study, it accounts only around 2\% (131). This implies that the industry could be an export-oriented but is not vital to the economy.

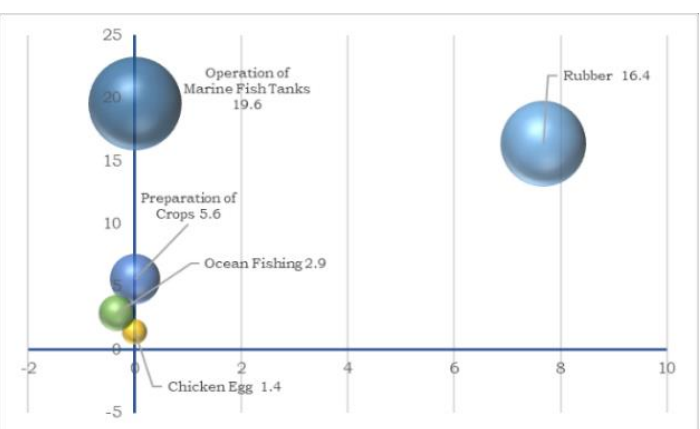

Figure 11. Agriculture sub-sector average Location Quotient, Zamboanga Peninsula, 20062012.

Ocean fishing is the second highest employment generator in the region next to rubber production. It is nearly 3 times more concentrated in the region but is having a negative $(-0.34)$ average percent change. As per assumption of the LQ, a high-LQ industry with declining LQ over time could be detrimental to the economy.

\section{Northern Mindanao}

Northern Mindanao is the fourth highest contributor to the total number of employments in the agriculture sector in the Philippines contributing $10 \%$ or around 17,049 number of employments in 2012.

Figure 12, displays the key industries in Northern Mindanao where cavendish banana is the highest employment generator. It contributes $44 \%$ to the total employment in the agriculture sector in Northern Mindanao in 2012 and recorded a positive average percent change in LQ over time implying that the employment generation is increasing. Hence, among the agriculture sub-sectors, growing of banana is an export-oriented industry and an economic base of the region. As an export-oriented, they bring money into the region, rather than simply circulating money that is already in the region.
Pineapple production is another economic base to be considered such that it is 5 times more concentrated in the region than average with its high number of employment accounting $23 \%$ to the total number of employments in the agriculture sector in the region in 2012 although it tags a negative positive percent change in LQ under the period under study.

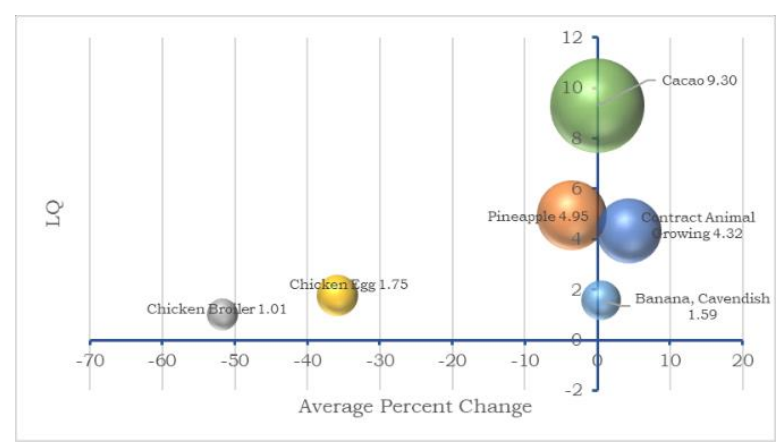

Figure 12. Agriculture sub-sector average Location Quotient, Northern Mindanao, 2006-2012.

In addition, growing of cacao and fertilizer application are explicit industries in the region. Growing of cacao is the only industry found in the region and thus, records the highest LQ for cacao production which is nearly 10 times more concentrated in the region than average. Although it only contributes around $1 \%$ to the total employment in the Northern Mindanao for the agriculture sector in 2012. This could also be an export-oriented but is not vital to the economy given the lower number of jobs generated.

\section{Davao Region}

Davao Region is the lead region to have the highest number of employments in the Philippine agriculture sector in 2012 accounting to nearly $23 \%$ and that is around 38,079 number of employments. The region is composed of diverse agriculture subsector contributing to the huge number of employments.

Figure 13 shows the Davao region's agrisubsector's average LQ. Just like Northern Mindanao, Davao region's highest employing industry is banana cavendish contributing nearly $80 \%$ to its total employment in the sector in 2012. This is actually the highest LQ value for cavendish banana among the regions. This implies that the industry can be an economic base of the region.

Meanwhile, dairy noticeably has the highest LQ value of 3.90. It posted a positive average percent change of around $83 \%$ between the 2009 and 2012 statistics. This is a potential export-oriented industry but with lower number of employments which infer that it is not vital to the economy. 


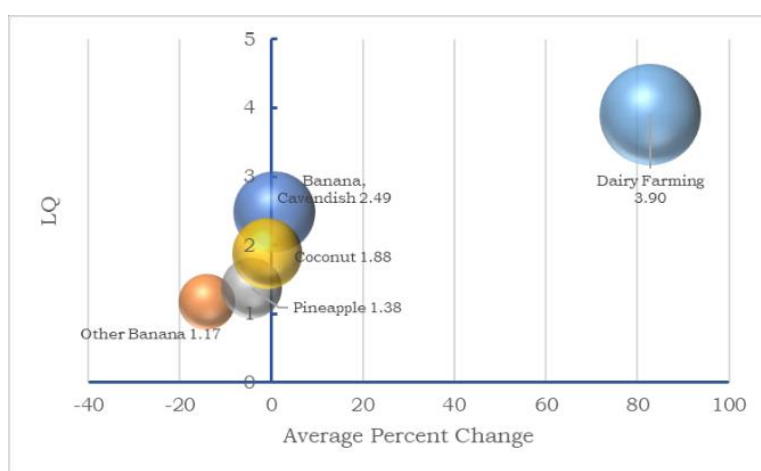

Figure 13. Agriculture sub-sector average Location Quotient, Davao Region, 2006-2012

\section{Soccsksargen}

Among the regions, SOCCSKSARGEN is the third next to Western Visayas with the highest contribution to the total number of employments in the Philippine agriculture sector in 2012 as shown in Figure 14. Contributing 18,459 number of employment or around $11 \%$ to the total employment generated by the sector in the said period. Cavendish banana forms the economic base of the region with LQ value of 2.49 and the highest employment generator contributing $50 \%$ to the total employment in the agriculture sector in the region in 2012.

Meanwhile, corn exhibits the highest LQ value of nearly 6 . This is the highest value among other regions in the period under study. However, its contribution to the total number of employments in the region for the agriculture sector is tagged only at nearly $3 \%$. It can be inferred that the industry can be an export based but is not vital to the regional economy base on the assumptions of the LQ.

Further, other industries lying on the Y-axis are operation of fishpond, coconut, paddy rice and dairy farming are other specialized industries in the region. However, these industries only posted lower number of employments of less than $1 \%$ to the total number of jobs in the agriculture sector in SOCCKSSARGEN in 2012.

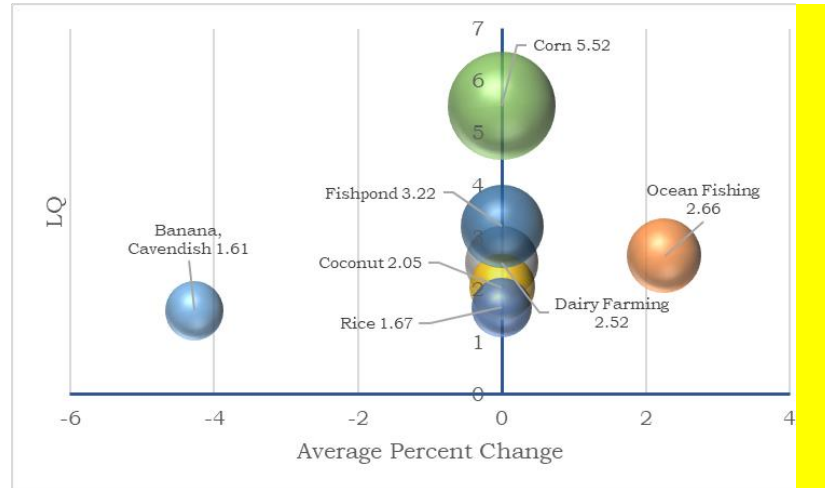

Figure 14. Agriculture sub-sector average Location Quotient, SOCCSKSARGEN, 2006-2012.

\section{Caraga Region}

Caraga Region's industry with the highest LQ is timber forest which is 50 times more concentrated in the region than the national average. This implies that the region is producing more than the local demand and thus, the industry is exportoriented. This satisfies being an economic base of the region if only the number of employments is also high. The number of jobs for the industry accounts $14 \%$ to the total number of jobs in the agriculture sector in the region in 2012.

Cavendish banana qualifies the region's economic base given the LQ value of almost 2 and it's the top employment generator among the agriculture sub-sector contributing 55\% to the total number of employments in the agri-sector in Caraga.

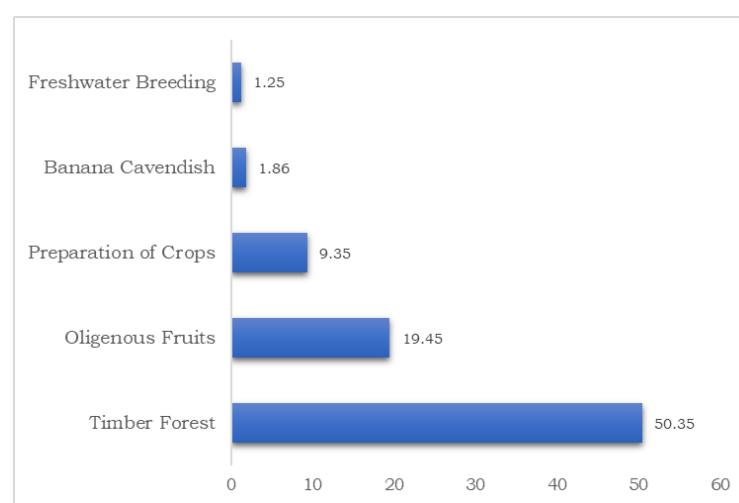

Figure 15. Agriculture sub-sector Location Quotient, CARAGA Region, 2012.

Further in Figure 15, it is evident that growing of oleaginous (oil producing) crop has the second highest LQ value. This is also the highest LQ computed among the regions in the Philippines. This could also form as another economic base of the region given the high number of employment accounting to around $25 \%$ or 617 jobs in 2012 .

\section{Autonomous Region of Muslim Mindanao (ARMM)}

The Autonomous Region of Muslim Mindanao (ARMM) contributes $1.68 \%$ to the total number of employments in the national agriculture sector in 2012. It is one of the regions with the least number of agriculture sub-sector with LQ of more than one. In a single shot, Figure 16 shows coconut as the primary industry with LQ value of 22.20. The region calculated the highest quotient in coconut next to MIMAROPA. The industry contributes $20 \%$ to the total number of employments in the regional agriculture sector in 2012. This satisfies the criterion that the industry is an export-oriented industry.

Rubber and Cavendish banana are two industries considered as economic base of the region. Rubber industry, although exhibits a negative average percent change is the top employment generator in 2012 contributing $79 \%$ or 
1620 jobs. Cavendish banana which is nearly 2 times more concentrated in the region than the national average is the top employment generator in 2008 contributing $48 \%$ to the total regional agri-sector employment.

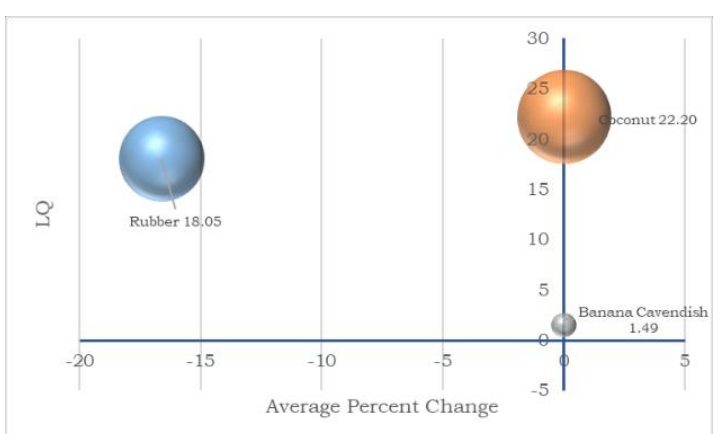

Figure 16. Agriculture sub-sector average Location Quotient, ARMM, 2006-2012.

\section{Extent of Relationship Between the Agriculture Industry Concentration and Agriculture Growth}

Table 1 shows that the correlation between the concentration and sectoral agriculture growth is positive however, it is not statistically significant (P>.005). This implies that there exists no relationship between the two variables.

This result is supported by the studies of Swaminathan et.al (2015), Ferreira et. al (2010), Gabe (2008), Hollis (2003) and Yotopoulos and Nugent as cited by Holz (2010) who found insignificant relationships between industry concentration and economic performance; and linkage and growth nexus. As to Hollis (2003), the higher the concentration in an industry within a country, the lower its share of world output and of net exports.

Moreover, the insignificant relationships between the concentration of the agriculture sector and measure of growth is somehow related to the study of Ernst and Sarabia as cited in Rey et.al (2016) that the growth in gross domestic product (output indicator) does not always have the expected positive impact on employment, since employment is the factor used in the computation of the location quotient coefficient. In addition, Machek and Špička (2013) states that productivity growth of agricultural companies does not necessarily move in the same direction as the growth of the economy.

The agriculture concentration does not have significant positive correlation with output indicator. This implies that the agriculture sector concentration is weak to affect output growth. This could be attributed to the impediments faced by the agriculture sector as also reflected by its declining trend performance.
Table 1. Correlation Result, Location Quotient and GVA in agriculture.

\begin{tabular}{lll}
\hline & & $\begin{array}{l}\text { GVA in } \\
\text { agriculture }\end{array}$ \\
\hline Location & Pearson & .071 \\
Quotient & $\begin{array}{l}\text { Correlation } \\
\text { Sig. (2-tailed) }\end{array}$ & $.592^{\mathrm{ns}}$ \\
\hline
\end{tabular}

\section{CONCLUSION}

The use of LQ has facilitated the identification of the key agriculture sub-sectors in each region in the Philippines. The identification of these key sub-sectors has provided picture of the trends of the performance of the sub-sectors in terms of its employment multiplier. This is so far the first mapping done for the agriculture sectors in the Philippines that used the LQ tool.

The null hypothesis that states that there is no significant correlation between the LQ and GVA in the agriculture sector was accepted. Regions with higher regional industry concentration does not necessarily have high GVA in the agriculture sector. However, this also reflect the impediments faced by the agriculture sector on the different factors that's why it is unable to effect positive development outcome.

\section{REFERENCES}

Aquino, A.P., Ani, P.A. \& Festejo, M.A. (2013). An Overview of Policies and Public Sector Investments in Philippine Agriculture. FFTC Agricultural Policy Articles. Taipei, Taiwan.

Boasson, E. (2002). The development and dispersion of industries at the country scale in the United States 1969-1996: An integration of Geographic Information Systems (GIS), Location Quotient, and Spatial Statistics. Dissertation. Proquest Dissertations Publishing. USA.

Creswell, J. W. (2010). Research Design: Qualitative, Quantitative, and Mixed Methods Approaches (4th ed.). London: SAGE.

EMSI (Economic Modelling and Specialists Inc.) (No Date). Understanding location quotient. Retrieved

from www.economicmodeling.com on March 16, 2017.

Ferreira, F., Goldszmith, R. \& Csillag, J. (2010). The regional concentration of industries and the performance of firms: a multilevel approach. Brazilian Administration Review. Vol.7. No.4. ISSN 1807-7692.

Gabe, T. (2008). City-industry agglomeration and changes in the geographic concentration of 
industry. The Review of Regional Studies. Vol.38, No.2. pp. 173-193.

Goschin, Z., Constantin, D., Roman, M., \& Ileanu, B. (No Date). Regional specialization and geographic concentration of industries in Romania. The Bucharest Academy of Economic Studies.

Hollis, A. (2003). Industrial concentration, output, and trade: An empirical exploration. Review of Industrial Organizations. Kluwer Academic Publishers. Netherlands. 22:103119.

Holz, C. (2010). The Unbalanced Growth Hypothesis and the Role of the State: the Case of China's State-owned Enterprises. Journal of Development Economics.

Imbs, J., Montenegro C., \& Wacziag R. (2012). Economic integration and structural change. Research Paper. From http://www.ipc.umich.edu/integration_waczi arg.pdf.

Macheck, O. \& Spicka, J. (2013). Measuring performance growth of agricultural sector: a total factor productivity approach.

International Journal of Economics and Statistics. Vol. 1, Issue 4.

Miller, M., Gibson, L. \& Wright, N. (1991). Location Quotient: A Basic Tool for Economic Development Analysis. Economic Development Review (Spring):65-68.

Morgan, J. (2004). The Role of Regional Industry Clusters in Urban Economic Development: An Analysis of Process and Performance. Dissertation. Proquest Dissertations Publishing. USA.

Philippine Development Plan (2017-2022).

Philippine Infrastructure Report Q1 2017 (2017). Business Monitor International.
Philippine Statistics Authority (PSA). (2014). 2006 Input-Output accounts of the Philippines. ISSN 1655-8928.

Philippines Agribusiness Report Q1 (2013). Business Monitor international. ISSN 20400438.

Pontus, B. \& Borgman, B. (2004). Geographical concentration, entrepreneurship and regional growth: Evidence from regional data in Sweden 1975-99. Regional Studies. Cambridge Vol. 38, Iss. 8.

Rey, I.U., Shakulikova, G.T., \& Kozhakhmetova, G.A. (2016). Labor factor efficiency in the agricultural Industry. International Journal of Environmental \& Science Education. Vol. 11, No. 17, 9679-9691.

Sheppard, S. \& Zhao, D. (2016). Regional concentration of industry in China: decentralized choices or a central plan?

Swaminathan, A., Gupta, A., Tiwari, A. \& Prakash, N. (2015). Concentration and efficiency in Indian manufacturing: A regional study. The IUP Journal of Applied Economics, Vol. XIV, No. 4, 201544.

World Bank (2017). Agriculture Overview. Accessed on August 11, 2018 from http://www.worldbank.org/en/topic/agricult ure/overview

Zepeda, L. (No Date). Agricultural investment, production capacity and productivity. Food Agriculture Organization. Accessed from www.fao.org /tempref/docrep/fao/003/x9447e/ on December 10, 2017. 